\section{REVISÃO SISTEMÁTICA SOBRE MODELOS EXPERIMENTAIS DE ASMA AGUDA E CRÔNICA INDUZIDOS COM EXTRATO DE ÁCARO DA POEIRA DOMÉSTICA}

\author{
SYSTEMATIC REVIEW ON EXPERIMENTAL MODELS OF ACUTE AND \\ CHRONIC ASTHMA INDUCED WITH HOUSE DUST MITE EXTRACT
}

\author{
Moisés Santos Dutra ${ }^{1}$, Cristian Roncada ${ }^{1}$, Rodrigo Godinho de Souza ${ }^{1}$, \\ Aline Andrea da Cunha ${ }^{1}$, Paulo Márcio Pitrez ${ }^{1}$
}

\section{RESUMO}

Clin Biomed Res. 2017;37(2):132-139

1 Programa de Pós-graduação em Pediatria e Saúde da Criança, Instituto de Pesquisas Biomédicas, Pontifícia Universidade Católica do Rio Grande do Sul (PUCRS). Porto Alegre, RS, Brasil.

Autor correspondente:

Paulo Márcio Pitrez

pmpitrez@pucrs.br

Instituto de Pesquisas Biomédicas,

Pontifícia Universidade Católica do Rio

Grande do Sul (PUCRS)

Av. Ipiranga, 6681.

90619-900, Porto Alegre, RS, Brasil.
Introdução: Asma é uma doença crônica das vias aéreas inferiores com elevada prevalência. Pesquisadores no mundo todo têm desenvolvido vários estudos experimentais em camundongos com o objetivo de entender melhor os mecanismos da doença e testar novas terapias. Ácaros estão presentes de forma abundante na poeira doméstica, sendo considerados os alérgenos mais comuns desencadeantes de asma alérgica. Este estudo objetiva apresentar e discutir desfechos inflamatórios no tecido pulmonar dos camundongos, verificar a diferença entre os modelos agudo e crônico de asma alérgica, tempo de exposição ao alérgeno, dose administrada e seu impacto nas pesquisas em modelos experimentais com asma.

Métodos: A revisão da literatura foi realizada em quatro bancos de dados (PubMed, Scielo, Scopus e ScienceDirect). Os artigos selecionados foram avaliados primeiramente por dois pesquisadores de forma independente, de acordo com os critérios de inclusão.

Resultados: Foram separados 126 artigos. Aplicados os critérios de inclusão e exclusão, somente 15 foram selecionados. São artigos que apresentaram diferentes protocolos de exposição ao HDM. A dose de HDM mais encontrada foi $100 \mu g$ seguida por $25 \mu \mathrm{g}$, e o tipo de modelo foi agudo.

Conclusão: No modelo agudo, observa-se um elevado nível de inflamação das vias aéreas. Já o modelo crônico reproduz melhor as características da asma em humanos, hiper-responsividade brônquica e remodelamento das vias aéreas.

Palavras-chave: Asma; ácaro; alérgeno; camundongos

\section{ABSTRACT}

Introduction: Asthma is a chronic disease of the lower airways with a high prevalence. Researchers worldwide have developed several experimental studies in mice with the goal of better understanding the mechanisms of the disease and testing new therapies. Mites are abundantly present in household dust, being considered the most common allergens triggering allergic asthma. This study aims to present and discuss inflammatory outcomes in the lung tissue of the mice, verify the difference between acute and chronic models of allergic asthma, time of exposure to the allergen, dose administered and its impact on research in experimental models with asthma.

Methods: Literature review was performed in four databases (PubMed, Scielo, Scopus and ScienceDirect). The selected articles were first evaluated by two researchers independently, according to the inclusion criteria.

Results: A total of 126 articles were separated. When the inclusion and exclusion criteria were applied, only 15 were selected. They are articles that presented different 
protocols of exposure to HDM. The most commonly found HDM dose was $100 \mu \mathrm{g}$ followed by $25 \mu \mathrm{g}$, and the model type was acute.

Conclusion: In the acute model, a high level of airway inflammation is observed. However, the chronic model better reproduces the characteristics of asthma in humans, bronchial hyperresponsiveness, and airway remodeling.

Keywords: Asthma; mite; allergen; mice

A asma é definida como uma doença crônica das vias aéreas inferiores, caracterizada por inflamação persistente e hiper-responsividade brônquica ${ }^{1}$. Mudanças estruturais das vias aéreas inferiores, incluindo espessamento da musculatura lisa, metaplasia epitelial e hiperplasia de células caliciformes são características observadas². Asma é a doença crônica mais comum na infância, sendo considerada um problema global de saúde ${ }^{3,4}$. No mundo todo aproximadamente 350 mil pessoas por ano são internadas por asma ${ }^{5}$. House duste mite (HDM) é um pequeno artrópode microscópico presente no habitat humano, considerado o principal desencadeante de asma alérgica ${ }^{6}$. O HDM penetra no epitélio da via aérea, estimulando a migração de células dendríticas para os linfonodos ${ }^{7}$.

Vários modelos de indução de asma em camundongos são desenvolvidos utilizando diversos alérgenos como: ovalbumina (OVA), HDM e pólen de vegetais ${ }^{8,9}$. Modelos agudo de resposta alérgica têm sido amplamente registrados na literatura, pois permitem elucidar mecanismos mais simples de respostas inflamatórias de curto prazo, níveis de $\operatorname{lgE}$, hiperplasia e hipertrofia epitelial. Apesar de serem utilizados com sucesso, apresentam algumas limitações: o influxo de células inflamatórias é constituído basicamente por eosinófilos, e muitas das características parecem ser resolvidas alguns dias após o desfecho da administração ${ }^{10}$. Já outros protocolos fazem uso de adjuvante, o qual intensifica a resposta Th2 desencadeada pelo sistema imune. Por outro lado, temos os modelos crônicos quando o alérgeno é administrado repetidas vezes, sem a necessidade de adjuvante. Apresenta resultados mais próximos da asma clínica como remodelamento das vias aéreas, espessamento da parede e produção de muco $^{10}$.

Por ser uma doença muito complexa e de grande prevalência, a asma alérgica tem sido muito estudada através de experimentos com camundongos. Os camundongos são os animais mais populares para estudos experimentais com asma, pois são de baixo custo, facilmente sensibilizados por alérgenos e demonstram hiper-responsividade das vias aéreas ${ }^{11}$. Assim, vários protocolos distintos têm sido publicados com modelos murinos de HDM. No entanto, não existe na literatura uma análise comparativa desses modelos experimentais (agudos e crônicos). Portanto, o presente estudo tem como objetivos apresentar e discutir os desfechos inflamatórios no tecido pulmonar dos camundongos, bem como verificar a diferença entre ambos os modelos, tempo de exposição ao alérgeno, dose administrada e seu impacto nas pesquisas em modelos experimentais de asma. Acreditamos que essa análise poderá auxiliar pesquisadores na tomada de decisão de qual modelo usar para responder perguntas mecanísticas ou pré-clínicas de intervenção em asma.

\section{MÉTODOS}

Foi aplicada uma lógica de pesquisa (revisão sistemática) em quatro bases de dados em saúde (PubMed, Scielo, Scopus e ScienceDirect) com a finalidade de apresentar e discutir os principais desfechos inflamatórios no tecido pulmonar dos camundongos, diferença entre os modelos e tempo de exposição ao alérgeno.

\section{Critérios de Inclusão}

Foram incluídos estudos experimentais com modelos murinos de indução de asma com HDM. Foram selecionados estudos publicados em revistas internacionais, no idioma de língua inglesa, utilizando extrato de HDM das empresas Greer (EUA), Alk Abelló (Espanha), Bencard Worthing (Reino Unido), e Biotecnology Charlottes Ville (EUA). Artigos sem essas informações foram excluídos.

\section{Estratégia de Busca}

Para realização da busca dos artigos usamos uma lógica baseada nos descritores específicos (em língua inglesa), junto com os operadores booleanos (AND e OR), usando parênteses () para delimitar intercalações dentro de uma lógica, assim como aspas (“") para identificar palavras compostas, aplicados da seguinte forma: ((HDM OR "House dust mite") AND Asthma AND "Murine Model").

As buscas foram realizadas nas bases de dados até o presente ano de 2017. A pesquisa foi realizada utilizando os campos do título (Title), palavras-chave (Keywords) e resumo (Abstract). Filtros como idioma do artigo e público alvo não foram adicionados 
na busca. Os artigos foram importados de seus bancos de dados utilizando o software específico para a elaboração de revisões sistemáticas StArt (State of the Art through Systematic Review) ${ }^{12}$. Para fins de relevância na seleção dos artigos, dois pesquisadores avaliaram de forma independente a seleção dos estudos.

\section{Qualidade Metodológica}

A qualidade dos artigos selecionados foi avaliada pelo sistema PRISMA ${ }^{13}$. Após, foi aplicado um checklist (figura 1) que verifica o nível de significância científica de cada artigo selecionado, composto por quatro fases: a) Identificação: busca dos artigos nos bancos de dados PubMed, Scielo, Scopus e Science Direct. b) Seleção: Os artigos duplicados foram excluídos a partir da leitura dos títulos e resumos. Obteve-se os artigos pré-selecionados. c) Elegibilidade: Realizamos leitura completa dos artigos. d) Inclusão: Inserção dos artigos elegíveis, conforme os critérios de inclusão pré-estabelecidos.

Ressalta-se que cada fase foi realizada separadamente por dois pesquisadores e analisada por um terceiro revisor. Os artigos selecionados pelos dois pesquisadores foram inclusos, já os artigos não selecionados foram excluídos. Os artigos selecionados por somente um pesquisador foram analisados pelo revisor, fase em que foram excluídos ou incluídos.

\section{Extração e Apresentação dos Dados}

A apresentação dos dados foi estruturada para demonstrar o desenho de seleção dos estudos (figura 1). Tabelas pré-formatadas foram utilizadas para registrar o autor principal, sexo e linhagem dos camundongos, protocolo de HDM aplicado, dose de HDM e tipo de exposição (tabela 1). Por fim, são apresentados os autores e os dados dos desfechos inflamatórios no pulmão e na função pulmonar (tabela 2).

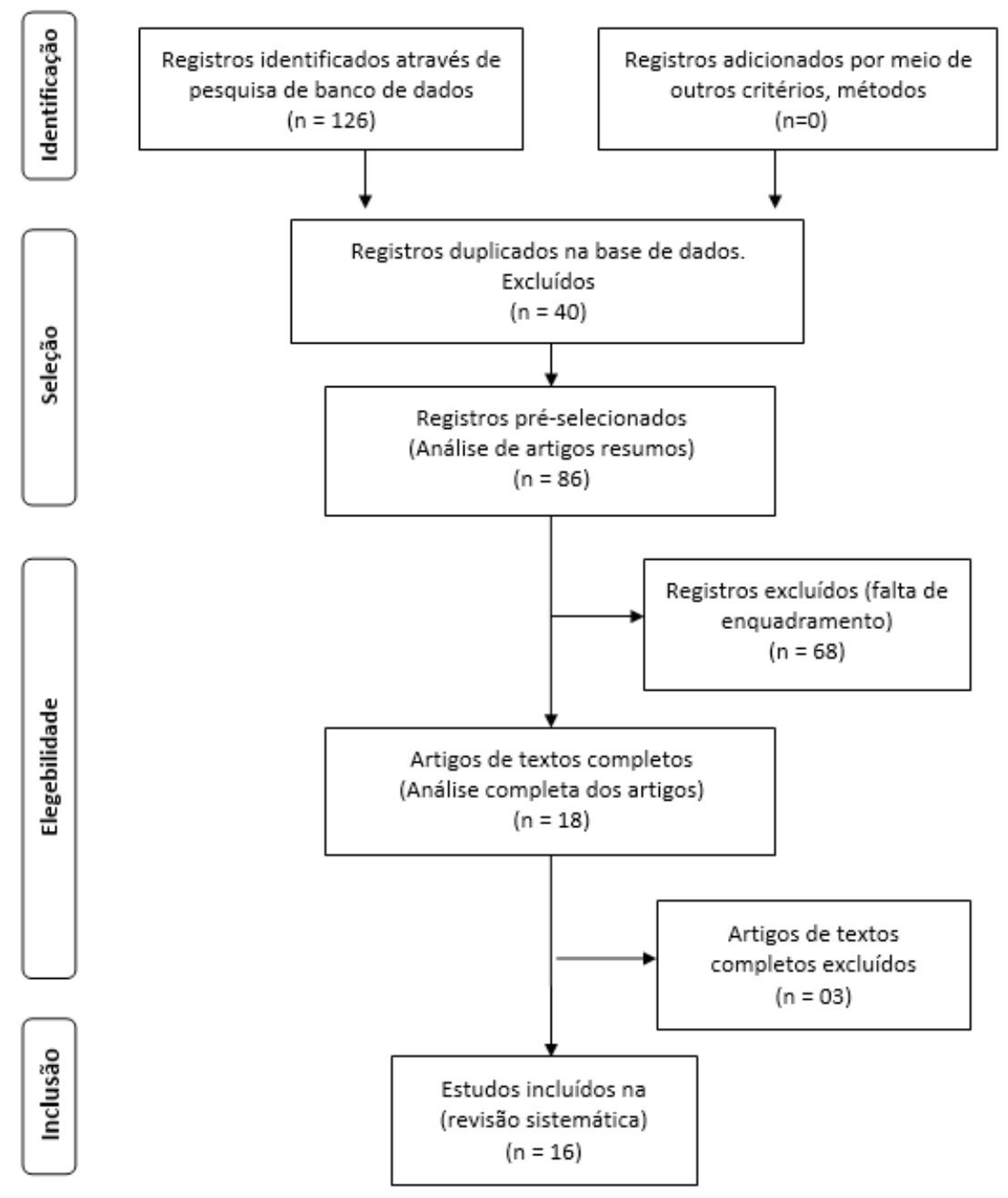

Figura 1: Fluxograma de elegibilidade e inclusão dos estudos. 
Tabela 1: Modelos murinos de exposição ao HDM.

\begin{tabular}{|c|c|c|c|c|}
\hline Autor & Sexo/linhagem & Protocolo de HDM aplicado & Dose do HDM & Exposição \\
\hline Piyadasa et al. (2016) $)^{14}$ & Macho, Balb/c & $\begin{array}{l}\text { Desafios i.n por } 5 \text { dias consecutivos } \\
\text { durante duas semanas. }\end{array}$ & $\begin{array}{c}35 \mu \mathrm{l} \text { of HDM } \\
(0.7 \mathrm{mg} / \mathrm{ml})\end{array}$ & Aguda \\
\hline $\begin{array}{l}\text { Seyedrezazadeh et al. } \\
\qquad(2015)^{15}\end{array}$ & Fêmeas, Balb/c & Sensibilização i.n nos dias $0,7,14$ & $\begin{array}{c}200,100 \\
100 \mu \mathrm{g} \\
\text { respectivamente }\end{array}$ & Crônica \\
\hline Zasłona et al. $(2014)^{16}$ & C57BL/6 & $\begin{array}{l}\text { Desafio orofaríngeo nos dias } 0,7,8, \\
\text { com eutanásia no dia } 9\end{array}$ & $100 \mu g$ & Aguda \\
\hline Chen et al. $(2013)^{17}$ & Fêmeas, Balb/c & $\begin{array}{c}\text { Desafio i.n } 5 \text { dias consecutivos/ } \\
\text { semana, durante } 5 \text { semanas } \\
\text { consecutivas, eutanásia no dia } 33 \text {. }\end{array}$ & $25 \mu \mathrm{g}$ & Crônica \\
\hline Draijer et al. $(2013)^{18}$ & $\begin{array}{l}\text { Machos e fêmeas, } \\
\text { Balb/c }\end{array}$ & $\begin{array}{c}\text { Protocolo \#1: desafio i.n no dia } 0 \text {, } \\
\text { seguido dos dias } 7-11 \text {, com eutanásia } \\
\text { no dia } 14 \text {. Protocolo \#2: desafio i.n } \\
3 x / \text { semana, por } 3 \text { semanas, com } \\
\text { eutanásia no dia } 21 \text {. Protocolo \#3: } \\
\text { desafio i.n nos dias } 0,7,14 \text { e } 21 \text {, com } \\
\text { eutanásia no dia } 24 \text {. }\end{array}$ & $\begin{array}{c}\text { Protocolo } \\
\# 1: 100 \mu \mathrm{g} \\
\text { (dia 0), } 10 \mu \mathrm{g} \\
\text { (dias } 7-11 \text { ). } \\
\text { Protocolo } \\
\text { \#2: } 25 \mu \mathrm{g} . \\
\text { Protocolo \#3: } \\
100 \mu \mathrm{g}\end{array}$ & $\begin{array}{l}\text { \#1: aguda; \#2: } \\
\text { crônica; \#3: } \\
\text { dado ausente }\end{array}$ \\
\hline Hagner et al. $(2013)^{19}$ & Fêmeas, Balb/c & $\begin{array}{c}\text { Desafio i.n nos dias } 0,7,14 \text { e } 21, \\
\text { eutanásia no dia } 22 .\end{array}$ & $100 \mu g$ & Aguda \\
\hline Kelada et al. $(2011)^{20}$ & $\begin{array}{l}\text { Machos, C57BL/6 } \\
\text { e BALB/cJ }\end{array}$ & $\begin{array}{l}\text { Sensibilização i.p nos dias } 1 \text { e } 7 . \\
\text { Desafio no dia } 14 \text { por via orotraqueal. }\end{array}$ & $\begin{array}{l}\text { Sensibilização: } \\
10 \mu \mathrm{g} . \\
\text { Desafio: } 50 \mu \mathrm{g} .\end{array}$ & Aguda \\
\hline Nikota et al. $(2011)^{21}$ & $\begin{array}{l}\text { Fêmeas, C57BL/6, } \\
\text { CD1 e BALB/C }\end{array}$ & $\begin{array}{l}\text { Desafio i.n por } 10 \text { dias consecutivos e } \\
\text { eutanásia após } 3 \text { dias. }\end{array}$ & $25 \mu \mathrm{g}$ & Aguda \\
\hline Tourdot et al. $(2011)^{22}$ & Fêmeas, BalB/c & $\begin{array}{l}\text { Sensibilização i.p. nos dias } 0 \text { e } 14 . \\
\text { Desafio por aerossol entre os dias } \\
\text { 21-24 por } 20 \text { min. Desafio reexpostos } \\
\text { ao HDM } 2 \text { dias consecutivos, com } \\
\text { eutanásia no dia seguinte. }\end{array}$ & $\begin{array}{l}\text { Sensibilização: } \\
20 \mu g \\
\text { (com alum). } \\
\text { Desafio: } \\
\text { 1, } 10 \text { e } 50 \mu g\end{array}$ & Aguda \\
\hline Marichal et al. $(2010)^{23}$ & $\begin{array}{l}\text { Fêmeas, WT } \\
\text { C57BI/6 }\end{array}$ & $\begin{array}{l}\text { Desafio i.n nos dias } 0,7,14, \text { e } \\
\text { eutanásia no dia } 17 .\end{array}$ & $100 \mu \mathrm{g}$ & Aguda \\
\hline Herrerias et al. $(2009)^{24}$ & Fêmeas, Balb/c & Desafios i.n por 10 dias consecutivos & $25 \mu \mathrm{g}$ & Aguda \\
\hline Matheu et al. (2009) ${ }^{25}$ & $\begin{array}{l}\text { Fêmeas, } \\
\text { C57BL/10 }\end{array}$ & $\begin{array}{l}\text { Sensibilização i.p nos dias } 0 \text { e } 4 \text {. } \\
\text { Desafio i.n nos dias } 14 \text { e 15, e OVA } \\
\text { com alum e eutanásia no dia } 16 \text {. }\end{array}$ & $\begin{array}{l}\text { Imunização: } \\
5 \mu \mathrm{g} \\
\text { (com alum). } \\
\text { Desafio: } 5 \mu \mathrm{g}\end{array}$ & Aguda \\
\hline Phipps et al. $(2009)^{26}$ & $\mathrm{BALB} / \mathrm{c}$ & $\begin{array}{l}\text { Sensibilização i.n nos dias } 0,1 \text { e } 2 \text {. } \\
\text { Desafio i.n. nos dias } 14,15,16 \text { e } 17, \text { e } \\
\text { eutanásia no dia seguinte. }\end{array}$ & $\begin{array}{l}\text { Sensibilização: } \\
25 \mu \mathrm{g} . \\
\text { Desafio: } 5 \mu \mathrm{g}\end{array}$ & Aguda \\
\hline Johnson et al. $(2008)^{27}$ & Fêmeas, Balb/c & $\begin{array}{c}\text { Desafio i.n por } 5 \text { dias consecutivos/ } \\
\text { semana, por } 5 \text { semanas e } 7 \text { semanas } \\
\text { consecutivas, respectivamente. } \\
\text { Eutanásia } 24 \text { horas após última dose } \\
\text { de BUD/FORM. }\end{array}$ & $25 \mu \mathrm{g}$ & Crônica \\
\hline
\end{tabular}

\begin{tabular}{|c|c|c|c|c|}
\hline Kim et al. $(2006)^{28}$ & Fêmeas, BALB/c & $\begin{array}{c}\text { Sensibilização s.c e ACF. Reforço } \\
7 \text { dias mais tarde com (ACF). Desafio } \\
\text { i.n } 6 \text { vezes/semana. }\end{array}$ & $\begin{array}{c}\text { Sensibilização: } \\
100 \mu g \\
\text { (com toxina } \\
\text { pertussis, } 24 \text { e } \\
72 \text { horas após } \\
\text { a primeira } \\
\text { imunização). } \\
\text { Desafio: } 10 \mu \mathrm{g}\end{array}$ & Crônica \\
\hline Inoue et al. $(2005)^{29}$ & Machos, $\mathrm{C} 3 \mathrm{H} / \mathrm{HeN}$ & $\begin{array}{c}\text { Sensibilização i.n. por } 4 \text { dias } \\
\text { consecutivos durante } 2 \text { semanas. }\end{array}$ & $100 \mu g$ & Aguda \\
\hline
\end{tabular}

HDM: house dust mite; BUD/FORM: budesonina/formoterol; ACF: adjuvante completo de Freund; i.n.: intranasal; i.p.: intraperitoneal. Alum: hidróxido de alumínio. 
Tabela 2: Resultados dos desfechos inflamatórios no pulmão e na função pulmonar.

\begin{tabular}{|c|c|}
\hline Autores & Desfechos inflamatórios no pulmão \\
\hline Piyadasa et al. $(2016)^{14}$ & $\begin{array}{l}\text { Aumento de eosinófilos e macrófagos, aumento da resistência das vias } \\
\text { aéreas. Análise histológica mostra um influxo celular significativo para a área } \\
\text { peribronquial e perivascular. }\end{array}$ \\
\hline Seyedrezazadeh et al. $(2015)^{15}$ & $\begin{array}{l}\text { Resposta fibrótica elevada, mudança estrutural das vias aéreas e aumento das } \\
\text { células inflamatórias }\end{array}$ \\
\hline Zasłona et al. $(2014)^{16}$ & Elevado número de eosinófilos e macrófagos no BALF. \\
\hline Chen et al. $(2013)^{17}$ & $\begin{array}{l}\text { Inflamação das vias aéreas e significativo aumento de eosinófilos, linfócitos e } \\
\text { neutrófilos. A exposição contínua causa hipersecreção de muco e hiperplasia de } \\
\text { células caliciformes. }\end{array}$ \\
\hline Draijer et al. (2013) ${ }^{18}$ & Alta porcentagem de eosinófilos e células T efetoras no tecido pulmonar. \\
\hline Hagner et al. $(2013)^{19}$ & Significativa inflamação eosinofílica e neutrofílica. \\
\hline Kelada et al. $(2011)^{20}$ & Significativo aumento de linfócitos, macrófagos e da produção de muco. \\
\hline Nikota et al. $(2011)^{21}$ & $\begin{array}{l}\text { Extensiva inflamação eosinofílica, enquanto que a exposição prolongada induziu } \\
\text { remodelamento das vias aéreas. }\end{array}$ \\
\hline Tourdot et al. $(2011)^{22}$ & $\begin{array}{l}\text { Inflamação eosinofílica e neutrofílica, aumento da hiper-responsividade } \\
\text { à metacolina, além do aumento da resistência brônquica e diminuição da } \\
\text { complacência. }\end{array}$ \\
\hline Marichal et al. $(2010)^{23}$ & $\begin{array}{l}\text { Inflamação eosinofílica, inflamação das vias aéreas hiperplasia das células } \\
\text { mucosas, hiper-reatividade das vias aéreas e aumento de IgE no soro. }\end{array}$ \\
\hline Herrerias et al. $(2009)^{24}$ & Significativa hiper-reatividade nas vias aéreas e forte inflação eosinofílica. \\
\hline Matheu et al. $(2009)^{25}$ & Alta porcentagem de eosinófilos e linfócitos nas vias aéreas. \\
\hline Phipps et al. $(2009)^{26}$ & $\begin{array}{l}\text { Inflamação eosinofílica, elevado número de células caliciforme. Secreção de } \\
\text { muco. Aumento da resistência e diminuição da complacência. }\end{array}$ \\
\hline Johnson et al. $(2008)^{27}$ & $\begin{array}{l}\text { Forte inflamação das vias aéreas, inflamação extensiva peribronquial e } \\
\text { perivascular. Aumento da produção de muco e da deposição de colágeno na via } \\
\text { aérea subepitelial. }\end{array}$ \\
\hline Kim et al. $(2006)^{28}$ & $\begin{array}{l}\text { Elevado infiltrado de células inflamatórias na submucosa das vias aéreas como } \\
\text { eosinófilo e macrófagos }\end{array}$ \\
\hline Inoue et al. $(2005)^{29}$ & $\begin{array}{l}\text { Alto número de eosinófilos e neutrófilos no BALF. Aumento de citocinas Th2 } \\
\text { como IL-13 E IL-5. }\end{array}$ \\
\hline
\end{tabular}

LBA: Lavado broncoalveolar; IgE: Imunoglobulina E; Th2: Célula Th2; IL13: Interleucina 13; IL-5: Interleucina 5.

\section{RESULTADOS}

Foram selecionados 126 artigos (PubMed: 49; ScienseDirect: 18; Scopus: 59 e Scielo: 0). Em uma primeira análise, 40 artigos foram excluídos por duplicidade (duas ou mais bases de dados), 68 artigos foram excluídos por não se enquadrarem nos critérios de inclusão e dois artigos foram excluídos por não usarem HDM como alérgeno. Portanto, para o presente estudo foram incluídos 16 artigos experimentais. Na Figura 1 é apresentado o fluxograma da evolução do estudo conforme o PRISMA ${ }^{13}$.

Para um maior esclarecimento do nosso estudo de revisão sistemática, os artigos selecionados estão resumidos em duas tabelas. Na Tabela 1 são apresentados os modelos usados na administração do HDM, e na Tabela 2 são exibidos os objetivos e resultados principais dos desfechos inflamatórios pulmonares de cada estudo elegível.

\section{DISCUSSÃO}

Os artigos selecionados neste estudo são de grande relevância para a ciência, trazendo informações importantes no entendimento da asma. Modelos murinos de asma com HDM exibem várias características da doença, pois muito se aproximam da doença que acomete os pacientes, tornando-se uma alternativa para investigar os mecanismos da asma e resposta a tratamentos ${ }^{10}$. No presente artigo, verificamos diferentes modelos de asma induzida por HDM, mostrando a diferença entre modelos agudos e crônicos, tempo de exposição ao alérgeno e dose administrada.

O modelo agudo de exposição ao HDM é uma forma mais rápida de obter resposta. Pode ser seguido ou não da presença de adjuvante ${ }^{10}$. Reproduz muitas características da asma, como elevado nível de inflamação das vias aéreas, IgE 
e células caliciformes ${ }^{10}$. Nos artigos selecionados observou-se que o modelo agudo foi usado em dez artigos. Os resultados mostram, em relação ao desfecho inflamatório no pulmão, que os grupos expostos ao HDM apresentam percentual elevado de eosinófilos, alto número de células nas contagens total, inflamação das vias aéreas, produção de células caliciformes, hiper-responsividade das vias aéreas, IgE total no soro, aumento de citocinas IL-4 e IL-5 e alto influxo celular na área peribronquial e perivascular ${ }^{14,16,18,19,21,23,24-26,29}$. Em relação à função pulmonar, o trabalho de Phipps et al. ${ }^{26}$ mostra um aumento da resistência e diminuição da complacência das vias aéreas. Outros estudos mostram que o influxo de células inflamatórias é predominantemente eosinofílico e que a hiperresponsividade brônquica é rapidamente revertida após cessar a exposição ao alérgeno ${ }^{30,31}$. Portanto, depreende-se que o modelo agudo de exposição ao HDM é um método importante para avaliar e obter resultados preliminares e sem uso de adjuvante. Os desfechos inflamatórios no tecido pulmonar são baseados em eosinófilos ${ }^{16,19,24,25}$.

Por outro lado, modelos crônicos de exposição ao alérgeno assemelham-se ao modelo agudo ${ }^{10}$. Na presente revisão sistemática foram selecionados cinco artigos de administração crônica. Os resultados mostram uma robusta inflamação e aumento da espessura das paredes das vias aéreas, com deposição de colágeno peribronquial e perivascular, produção de muco, expressão da citocina actina alfa de músculo liso ( $\alpha$-SMA) e hiper-responsividade brônquica à metacolina ${ }^{15,17,18,22}$. Logo, modelos crônicos fornecem desfechos mais próximos à asma clínica com resultados sobre remodelamento das vias aéreas, espessamento da parede, e aumento da produção de muco. O protocolo de HDM aplicado tende a ser de longo prazo, sendo indicado para reproduzir a asma crônica, mais agressiva ${ }^{17,18,27,28}$. Apesar disso o modelo crônico apresenta algumas limitações, como, por exemplo, em camundongos a inflamação não fica restrita às vias aéreas condutoras, já nos seres humanos a inflamação e remodelamento no parênquima pulmonar são observados. Além disso, para Kumarr ${ }^{30}$ não ocorre o recrutamento de mastócitos no epitélio das vias aéreas.

Outra análise importante é a dose de HDM. Observa-se na Tabela 1 que a dose mais usada foi de $100 \mu \mathrm{g}$. Os resultados desses trabalhos mostram que o número de células totais e diferenciais no lavado broncoalveolar (BAL) é significativamente alto, assim como a inflamação das vias aéreas e a produção de células caliciformes ${ }^{16,19,23,29}$. A contagem total e diferencial das células, o nível de lgE no soro e a resistência das vias aéreas à metacolina também são elevadas. Já com o modelo crônico, a mesma dose apresenta extensiva inflamação peribronquial e perivascular, produção de muco e deposição de colágeno ${ }^{17,27}$.

A segunda dose mais usada foi de $25 \mu \mathrm{g}$. Os resultados demostraram que a hiper-responsividade das vias aéreas, inflamação eosinofílica, contagem total de células, e IL-13 aumentaram quando comparado com o grupo controle ${ }^{21,24}$. Outro dado importante que nosso estudo demonstra é o uso de adjuvante (alum). $\mathrm{O}$ adjuvante intensifica a resposta Th2 pelo sistema imune ${ }^{32}$. Nos artigos cujo adjuvante foi usado os níveis de IgE específica para HDM e total no soro aumentaram no grupo exposto ao HDM, assim como as citocinas IL-4, IL-5 e IFN-gama, e a hiper-responsividade das vias aéreas ${ }^{21,33}$.

Apesar do modelo utilizado e a dose administrada serem fundamentais para o desenvolvimento da doença, os resultados não dependem tão somente do modelo ou dose. A linhagem do camundongo, o sexo e a via de administração do alérgeno são fatores que influenciam no desfecho ${ }^{31}$.

HDM é um alérgeno ambiental de extrema importância, derivado de ácaros da poeira doméstica que estão presentes em todos os ecossistemas e cultivam diversos habitats. Apesar de vários grupos científicos terem desenvolvido diferentes modelos de exposição ao HDM, o objetivo principal de todos é de reproduzir as características clínicas da doença, desenvolver novas terapias e avaliar o efeito de novos fármacos ${ }^{10}$.

Nosso estudo apresenta algumas limitações. Os artigos que utilizaram, como alérgeno, proteínas recombinante Der f 1, Der f 2 ou Blot 11 para indução do modelo experimental de asma aguda e crônica não foram incluídos ${ }^{34,35}$. Além disso, não foi possível mensurar o número de camundongos empregado em cada artigo avaliado ${ }^{36}$.

Concluindo, nosso artigo mostra diferentes estudos de protocolos de indução de asma com HDM. O tempo de exposição ao HDM influencia nos resultados finais, bem como a dose usada. Os modelos de indução de asma crônico e agudo são importantes para o entendimento da asma. Os modelos agudos são geralmente usados para elucidar e entender respostas imunológicas e inflamatórias na asma ${ }^{10}$ e os modelos crônicos oportunizam a investigação das mudanças estruturais das vias aéreas ${ }^{36}$.

\section{Conflito de interesse}

Os autores declaram não ter nenhum conflito de interesse. 


\section{REFERÊNCIAS}

1. Bousquet J. Global initiative for asthma (GINA) and its objectives. Clin Exp Allergy. 2000;30(s1 Suppl 1):2-5. PMid:10849466. http://dx.doi.org/10.1046/j.13652222.2000.00088.x.

2. Bousquet J, Jeffery PK, Busse WW, Johnson M, Vignola AM. Asthma: from bronchoconstriction to airways inflammation and remodeling. Am J Respir Crit Care Med. 2000;161(5):172045. PMid:10806180. http://dx.doi. org/10.1164/ajrccm.161.5.9903102.

3. Beasley R. Worldwide variation in prevalence of symptoms of asthma, allergic rhinoconjunctivitis, and atopic eczema: ISAAC. The International Study of Asthma and Allergies in Childhood (ISAAC) Steering Committee. Lancet. 1998;351(9111):122532. PMid:9643741. http://dx.doi. org/10.1016/S0140-6736(97)07302-9.

4. Bousquet J, Mantzouranis E, Cruz AA, Aït-Khaled N, Baena-Cagnani $\mathrm{CE}$, Bleecker ER, et al. Uniform definition of asthma severity, control, and exacerbations: document presented for the World Health Organization Consultation on Severe Asthma. J Allergy Clin Immunol. 2010;126(5):926-38. PMid:20926125. http://dx.doi.org/10.1016/j. jaci.2010.07.019.

5. IV Diretizes Brasileiras para o manejo da asma. J Bras Pneumol. 2006;32(Supl 7):S44774. PMid:17420905. http:// dx.doi.org/10.1590/S180637132006001100002.

6. Calderón MA, Linneberg A, KleineTebbe J, De Blay F, Hernandez Fernandez de Rojas D, Virchow $\mathrm{JC}$, et al. Respiratory allergy caused by house dust mites: what do we really know? J Allergy Clin Immunol. 2015;136(1):38-48. PMid:25457152. http://dx.doi.org/10.1016/j. jaci.2014.10.012.

7. Lambrecht BN, Hammad H. The role of dendritic and epithelial cells as master regulators of allergic airway inflammation. Lancet. 2010;376(9743):835-43. PMid:20816550. http://dx.doi. org/10.1016/S0140-6736(10)61226-3.

8. Buday T, Plevkova J. House dust mite allergy models: reliability for research of airway defensive mechanisms. Open J Mol Integr Physiol. 2014;4(3):27-35. http://dx.doi. org/10.4236/ojmip.2014.43004.

9. Parreira C, Rodrigues AM, Gualdi LP, Cao RG, de Souza RG, Pereira AC. Novas alternativas para protocolos com modelos murinos de asma. Sci Med. 2012;22:71-80.

10. Nials AT, Uddin S. Mouse models of allergic asthma: acute and chronic allergen challenge. Dis Model Mech. 2008;1(4-5):213-20. PMid:19093027. http://dx.doi.org/10.1242/dmm.000323.

11. Zosky GR, Sly PD. Animal models of asthma. Clin Exp Allergy. 2007;37(7):973-88. PMid:17581191. http://dx.doi.org/10.1111/j.13652222.2007.02740.x.

12. Zamboni A, Fabbri S. StArt: uma ferramenta computacional de apoio à revisão sistemática. In: Anais do Congresso Brasileiro de Software (CBSoft'10); 2010; Salvador, Brasil. Salvador; 2010. p. 91-6.

13. Liberati A, Altman DG, Tetzlaff J, Mulrow C, Gøtzsche PC, loannidis JP, et al. The PRISMA statement for reporting systematic reviews and meta-analyses of studies that evaluate health care interventions: explanation and elaboration. Ann Intern Med. 2009;151(4):W65-94. PMid:19622512. http://dx.doi.org/10.7326/0003-4819151-4-200908180-00136.

14. Piyadasa $\mathrm{H}$, Altieri A, Basu $\mathrm{S}$, Schwartz J, Halayko AJ, Mookherjee N. Biosignature for airway inflammation in a house dust mitechallenged murine model of allergic asthma. Biol Open. 2016;5(2):11221. PMid:26740570. http://dx.doi. org/10.1242/bio.014464.

15. Seyedrezazadeh E, Kolahian S, Shahbazfar AA, Ansarin K, Pour Moghaddam M, Sakhinia M, et al. Effects of the flavanone combination hesperetin-naringenin, and orange and grapefruit juices, on airway inflammation and remodeling in a murine asthma model. Phytother Res. 2015;29(4):591-8. PMid:25640915. http://dx.doi.org/10.1002/ptr.5292.

16. Zasłona Z, Przybranowski S, Wilke $\mathrm{C}$, van Rooijen N, Teitz-Tennenbaum $\mathrm{S}$, Osterholzer JJ, et al. Resident alveolar macrophages suppress, whereas recruited monocytes promote, allergic lung inflammation in murine models of asthma. $J$
Immunol. 2014;193(8):4245-53. PMid:25225663. http://dx.doi. org/10.4049/jimmunol.1400580.

17. Chen ZG, Zhang TT, Li HT, Chen FH, Zou XL, Ji JZ, et al. Neutralization of TSLP inhibits airway remodeling in a murine model of allergic asthma induced by chronic exposure to house dust mite. PLoS One. 2013;8(1):e51268. PMid:23300949. http://dx.doi.org/10.1371/journal. pone.0051268.

18. Draijer $C$, Robbe $P$, Boorsma CE, Hylkema MN, Melgert BN. Characterization of macrophage phenotypes in three murine models of house-dust-mite-induced asthma. Mediators Inflamm. 2013;2013:632049.

19. Hagner S, Harb H, Zhao M, Stein $\mathrm{K}$, Holst O, Ege MJ, et al. Farmderived Gram-positive bacterium Staphylococcus sciuri W620 prevents asthma phenotype in HDM- and OVA-exposed mice. Allergy. 2013;68(3):322-9. PMid:23369007. http://dx.doi.org/10.1111/all.12094.

20. Kelada SN, Wilson MS, Tavarez U, Kubalanza K, Borate B, Whitehead GS, et al. Strain-dependent genomic factors affect allergen-induced airway hyperresponsiveness in mice. Am J Respir Cell Mol Biol. 2011;45(4):81724. PMid:21378263. http://dx.doi. org/10.1165/rcmb.2010-0315OC.

21. Nikota JK, Botelho FM, Bauer CM, Jordana M, Coyle AJ, Humbles AA, et al. Differential expression and function of breast regression protein 39 (BRP-39) in murine models of subacute cigarette smoke exposure and allergic airway inflammation. Respir Res. 2011;12(1):39. PMid:21473774. http://dx.doi. org/10.1186/1465-9921-12-39.

22. Tourdot S, Airouche S, Berjont N, Silveira A, Mascarell L, Jacquet $A$, et al. Evaluation of therapeutic sublingual vaccines in a murine model of chronic house dust mite allergic airway inflammation. Clin Exp Allergy. 2011;41(12):1784-92. PMid:22092967. http://dx.doi.org/10.1111/j.13652222.2011.03865.x.

23. Marichal T, Bedoret D, Mesnil C, Pichavant M, Goriely S, Trottein $F$, et al. Interferon response factor 3 is essential for house dust miteinduced airway allergy. J Allergy Clin Immunol. 2010;126(4):836-44. 
e13. PMid:20673978. http://dx.doi. org/10.1016/j.jaci.2010.06.009.

24. Herrerias A, Torres R, Serra M, Marco A, Pujols L, Picado C, et al. Activity of the cyclooxygenase 2-prostaglandin-E prostanoid receptor pathway in mice exposed to house dust mite aeroallergens, and impact of exogenous prostaglandin E2. J Inflamm (Lond). 2009;6(1):30. PMid:19878559. http://dx.doi. org/10.1186/1476-9255-6-30.

25. Matheu V, Berggård $K$, Barrios Y, Barrios Y, Arnau MR, Zubeldia MJ, et al. Impact on allergic immune response after treatment with vitamin A. Nutr Metab (Lond). 2009;6(1):44. PMid:19852821. http://dx.doi. org/10.1186/1743-7075-6-44.

26. Phipps S, Lam CE, Kaiko GE, Foo SY, Collison A, Mattes J, et al. Toll//L-1 signaling is critical for house dust mitespecific helper T cell type 2 and type 17 [corrected] responses. Am J Respir Crit Care Med. 2009;179(10):88393. PMid:19246719. http://dx.doi. org/10.1164/rccm.200806-974OC.

27. Johnson JR, Pacitto SR, Wong J, Archer EW, Eirefelt S, Miller-Larsson A, et al. Combined budesonide/ formoterol therapy in conjunction with allergen avoidance ameliorates house dust mite-induced airway remodeling and dysfunction. Am J Physiol Lung
Cell Mol Physiol. 2008;295(5):L7808. PMid:18776055. http://dx.doi. org/10.1152/ajplung.90229.2008.

28. Kim N, Kwon SS, Lee J, Kim S, Yoo TJ. Protective effect of the DNA vaccine encoding the major house dust mite allergens on allergic inflammation in the murine model of house dust mite allergy. Clin $\mathrm{Mol}$ Allergy. 2006;4(1):4. PMid:16504003. http://dx.doi.org/10.1186/1476-7961-44.

29. Inoue K, Takano H, Shiga A, Fujita $\mathrm{Y}$, Makino H, Yanagisawa R, et al. Effects of volatile constituents of a rosemary extract on allergic airway inflammation related to house dust mite allergen in mice. Int $\mathrm{J} \mathrm{Mol} \mathrm{Med.}$ 2005;16(2):315-9. PMid:16012768.

30. Kumar RK, Foster PS. Modeling allergic asthma in mice: pitfalls and opportunities. Am J Respir Cell Mol Biol. 2002;27(3):26772. PMid:12204888. http://dx.doi. org/10.1165/rcmb.F248.

31. McMillan SJ, Lloyd CM. Prolonged allergen challenge in mice leads to persistent airway remodelling. Clin Exp Allergy. 2004;34(3):497507. PMid:15005746. http:// dx.doi.org/10.1111/j.13652222.2004.01895.x.

32. Gualdi LP, Pereira AC, Masiero L, Nuñez NK, Cao R, Pitrez PM.
Modelos murinos para pesquisas em asma: uma análise crítica atualizada. Scientia Medica. 2010;20:236-42.

33. Chang YS, Kim YK, Jeon SG, Kim SH, Kim SS, Park HW, et al. Influence of the Adjuvants and Genetic Background on the Asthma Model Using Recombinant Der $\mathrm{f} 2$ in Mice. Immune Netw. 2013;13(6):295300. PMid:24385949. http://dx.doi. org/10.4110/in.2013.13.6.295.

34. Ahn JH, Kim CH, Kim YH, Kim SJ, Lee SY, Kim YK, et al. Inflammatory and remodeling events in asthma with chronic exposure to house dust mites: a murine model. J Korean Med Sci. 2007;22(6):1026-33. PMid:18162718. http://dx.doi.org/10.3346/ jkms.2007.22.6.1026.

35. Inoue K, Takano H, Shiga A, Fujita Y, Makino H, Yanagisawa R, et al. Effects of volatile constituents of a rosemary extract on allergic airway inflammation related to house dust mite allergen in mice. Int $\mathrm{J} \mathrm{Mol} \mathrm{Med.}$ 2005;16(2):315-9. PMid:16012768.

36. Brewer JM, Conacher M, Hunter CA, Mohrs M, Brombacher F, Alexander J. Aluminium hydroxide adjuvant initiates strong antigen-specific Th2 responses in the absence of IL-4- or IL-13-mediated signaling. J Immunol. 1999;163(12):6448-54. PMid:10586035.

Recebido: Mar 09, 2017 Aceito: Jun 15, 2017 